\title{
U.S. Maternal Mortality Within a Global Context: Historical Trends, Current State, and Future Directions
}

\author{
Regine A. Douthard, MD, MPH, ${ }^{1}$ Iman K. Martin, PhD, MPH, MSc, ${ }^{2}$ \\ Theresa Chapple-McGruder, $\mathrm{PhD}, \mathrm{MPH}{ }^{3}$ Ana Langer, MD, ${ }^{4}$ and Soju Chang, MD, MPH ${ }^{5}$
}

\begin{abstract}
In the United States, despite significant investment and the efforts of multiple maternal health stakeholders, maternal mortality (MM) has reemerged since 1987 and MM disparity has persisted since 1935. This article provides a review of the U.S. MM trajectory throughout its history up to its current state. From this longitudinal perspective, MM trends and themes are evaluated within a global context in an effort to understand the problems and contributing factors. This article describes domestic and worldwide strategies recommended by maternal health stakeholders to reduce MM.
\end{abstract}

Keywords: maternal mortality, United States, global context, disparity, strategies

\section{Introduction}

M ATERNAL MORTALITY (MM) is widely acknowledged as a general indicator of the overall health of a population, of the status of women in society, and of the functioning of the health system." 1 The Centers for Disease Control and Prevention (CDC) and the World Health Organization (WHO) use different terms and measures to characterize MM (Box 1), ${ }^{2-6}$ but the maternal mortality ratio (MMR), calculated as the number of maternal deaths per 100,000 live births, is a widely utilized measure worldwide. ${ }^{2}$ Henceforth in this article, MMR will be displayed by its numerator only. Although the estimated global MMR has declined by $45 \%$, decreasing from 385 in 1990 to 211 in 2017, the estimated MMR in the United States has increased by $58 \%$, from 12 in 1990 to 19 in 2017 (Table 1). ${ }^{2,7}$ This article analyzes worldwide practices, data, and literature to establish future objectives to reduce MM in the United States.

\section{Global Context}

In 2000, the United Nations formed a global partnership to reduce world poverty and set eight Millennium Development
Goals (MDGs), including a goal to improve maternal health (target: reduce MMR by three quarters between 1990 and 2015). ${ }^{8}$ Building on the momentum of these MDGs, the United Nations established 17 Sustainable Development Goals, including a goal to ensure healthy lives and promote wellbeing for all, with a target of reducing the global MMR to $<70$ by $2030 .{ }^{9}$

Despite the decline of the estimated global MMR, disparity among countries is high, with $99 \%$ of preventable MM occurring in low- and middle-income countries. MM disparity is also high within countries, with a higher risk of MM among the most vulnerable segments of society (Table 1). ${ }^{10}$ In the United Kingdom, where overall MMR has been steadily low, MM disparity occurs along racial and ethnic lines. Compared with White women, Black women, women of mixed ethnicity, and Asian women have a higher risk of dying during pregnancy or up to 6 weeks post partum. ${ }^{11}$

Several reports have described the international efforts addressing MM. In 2015, WHO established a strategic framework toward Ending Preventable Maternal Mortality using guiding principles, crosscutting actions, and strategic objectives (Box 2). ${ }^{10}$ In 2018, the Health Resources and Services Administration (HRSA) held the HRSA Maternal Mortality

\footnotetext{
${ }^{1}$ Office of Research on Women's Health, Office of the Director, National Institutes of Health, Bethesda, Maryland, USA.

${ }^{2}$ Division of Blood Diseases and Resources, National Heart, Lung, and Blood Institute, National Institutes of Health, Bethesda, Maryland, USA.

${ }^{3}$ Division of Healthy Start and Perinatal Services, Maternal and Child Health Bureau, Health Resources and Services Administration, Rockville, Maryland, USA.

${ }^{4}$ Department of Global Health and Population, Harvard T.H. Chan School of Public Health, Boston, Massachusetts, USA.

${ }^{5}$ Division of Clinical Innovation, National Center for Advancing Translational Sciences, National Institutes of Health, Bethesda, Maryland, USA.

(C) Regine A. Douthard et al. 2021; Published by Mary Ann Liebert, Inc. This Open Access article is distributed under the terms of the Creative Commons Attribution Noncommercial License (http://creativecommons.org/licenses/by-nc/4.0/) which permits any noncommercial use, distribution, and reproduction in any medium, provided the original author(s) and the source are cited.
}

Correction added on February 19, 2021 after first online publication of November 18, 2020: The article reflects Open Access, with copyright transferring to the author(s), and a Creative Commons Attribution Noncommercial License (CC-BY-NC) added (http:// creativecommons.org/licenses/by-nc/4.0/). 
Box 1. TERMS AND Definitions

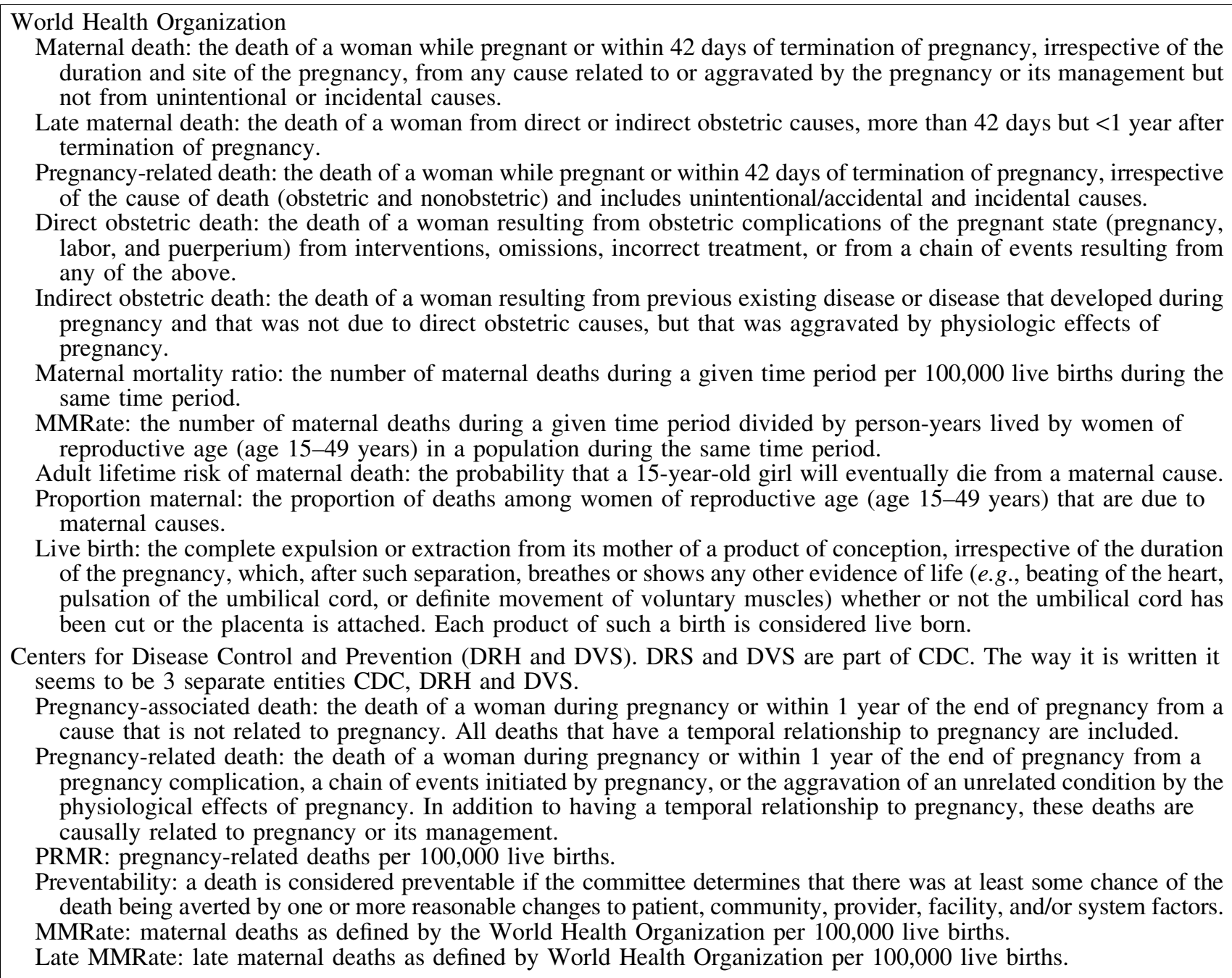

DRH, Division of Reproductive Health; DVS, Division of Vital Statistics; MMRate, maternal mortality rate; PRMR, Pregnancy-Related Mortality Ratio.

DVS uses the term MMRate (equivalent measure of WHO's maternal mortality ratio), and DRH uses the term PRMR. DVS's MMRate term is referred as MMR in the text.

Source: World Health Organization (WHO), ${ }^{2}$ Hoyert and Miniño, ${ }^{3}$ Petersen et al., ${ }^{4}$ St. Pierre et al., ${ }^{5}$ and Davis et al., ${ }^{6}$ Hoyert. ${ }^{17}$

Summit. At this international summit, a group of subject-matter experts from Brazil, Canada, Finland, India, Rwanda, the United Kingdom, and the United States discussed promising global practices and identified areas, where actions could decrease MM (Box 2). ${ }^{12}$ A 2020 report examining U.S. birth settings, a crucial component of maternity care, described important common practices in Australia, Canada, the Netherlands, and the United Kingdom. These countries were all committed to integrating care across birth providers, ranging from well-trained midwives attending uncomplicated deliveries to highly specialized obstetricians. They also supported seamless transfer across, out of, and into hospital maternity care systems; universal access to primary and maternity care before, during, and after pregnancy; and adoption of respectful care and respect for maternal autonomy. ${ }^{13}$ It is important to note that the MMR in these other high-income countries is significantly lower than in the United States (Table 1). ${ }^{2}$ Thus, the United States has an opportunity to adapt to its context those strategies that have proven successful in improving MM in other countries.

\section{Historical Trends}

In 1990, the U.S. Department of Health and Human Services (HHS) developed a national agenda for a healthier nation. Reducing the nation's MMR was a key maternal, infant, and child health indicator in the Healthy People 2000 objectives (target: 3.3; baseline 1987: 6.6) and Healthy People 2010 (target: 4.3; baseline 1999: 9.9). This objective has been updated in Healthy People 2020 (target 11.4; baseline 2007: 12.7). ${ }^{14-16}$ The CDC monitors MM through the National Vital Statistics System (NVSS) administered by the Division of Vital Statistics (DVS) and Pregnancy Mortality Surveillance System (PMSS), managed by the Division of Reproductive Health (DRH) (Fig. 1). ${ }^{3-5,17-25}$ DVS uses the term MMR, whereas DRH uses the term Pregnancy-Related Mortality Ratio (PRMR). 3,4,6 In addition to DVS and DRH, state and local Maternal Mortality Review Committees (MMRCs), composed of multidisciplinary members, play a pivotal role in providing systematic review and determining 
Table 1. Trends in Estimates of Maternal Mortality Ratio, Lifetime Risk, by Selected Countries, World Health Organization Region, and World Bank Income Group, 1990-2017

\begin{tabular}{|c|c|c|c|c|c|c|c|c|}
\hline \multirow[b]{2}{*}{ Year } & \multicolumn{7}{|c|}{ Maternal mortality ratio } & \multirow{2}{*}{$\begin{array}{l}\text { Lifetime risk of materna } \\
\text { death } 1 \text { in } \ldots 2017\end{array}$} \\
\hline & 1990 & 1995 & 2000 & 2005 & 2010 & 2015 & 2017 & \\
\hline World & 385 & 369 & 342 & 296 & 248 & 219 & 211 & 190 \\
\hline Australia & 8 & 8 & 7 & 5 & 5 & 6 & 6 & 8200 \\
\hline Canada & 7 & 9 & 9 & 11 & 11 & 11 & 10 & 6100 \\
\hline Netherlands & 12 & 13 & 13 & 11 & 7 & 6 & 5 & 11,900 \\
\hline United Kingdom & 10 & 11 & 10 & 11 & 10 & 8 & 7 & 8400 \\
\hline United States & 12 & 12 & 12 & 13 & 15 & 18 & 19 & 3000 \\
\hline \multicolumn{9}{|l|}{ WHO Region } \\
\hline Africa & 965 & 914 & 857 & 735 & 615 & 548 & 525 & 39 \\
\hline America & 102 & 89 & 73 & 68 & 64 & 60 & 59 & 850 \\
\hline South East Asia & 525 & 438 & 355 & 280 & 214 & 165 & 152 & 280 \\
\hline Europe & 44 & 42 & 27 & 22 & 17 & 14 & 13 & 4300 \\
\hline Eastern Mediterranean & 362 & 340 & 330 & 275 & 220 & 175 & 164 & 170 \\
\hline Western Pacific & 114 & 89 & 75 & 61 & 51 & 43 & 41 & 1400 \\
\hline \multicolumn{9}{|l|}{ World Bank Income Group } \\
\hline Low income & 1020 & 944 & 833 & 696 & 573 & 491 & 462 & 45 \\
\hline Lower middle income & 532 & 470 & 428 & 363 & 302 & 265 & 254 & 140 \\
\hline Upper middle income & 117 & 101 & 69 & 61 & 51 & 44 & 43 & 1200 \\
\hline High income & 27 & 26 & 12 & 11 & 11 & 11 & 11 & 5400 \\
\hline
\end{tabular}

Australia, Canada, the Netherlands, and the United Kingdom were selected because these countries were comparable to the United States as high-income countries with relatively robust data on birth settings and outcomes from their vital statistics systems. ${ }^{13}$

WHO, World Health Organization.

Source: years 1990 and $1995^{7}$; years $2000,2005,2010,2015,2017 .^{2}$

the risk factors, causes, and preventable drivers of maternal deaths. ${ }^{5,6,24}$ Two MMRCs were formed in the early 1930s; by 2018 that number had increased to include MMRCs in 45 states and the District of Columbia. ${ }^{26}$

One of the greatest public health achievements of the 20th century in the United States was the decline of MMR from $>800$ in 1900 to its lowest point of 6.6 in 1987 (Fig. 1). ${ }^{17}$ The steady decline of MMR over these 8.5 decades might be attributed to several factors: environmental interventions; improvements in nutrition, surveillance and monitoring of diseases, access to health care, and standard of living; advances in clinical medicine; increases in education; and technical and political changes implemented over time (e.g., MM reviews in the 1930s, shift from home to hospital births in the 1940s, use of antibiotics and transfusions in the 1950s, and implementation of Medicaid in the 1960s). ${ }^{13,27,28}$ However, MMR gradually reversed course and doubled from 6.6 in 1987 to 12.1 in $2003 .{ }^{17}$ Similarly, an ascending trend for PRMR from 7.2 in 1987 to 16.9 in 2016 was observed (Fig. 1). ${ }^{25}$ Contributing factors to the increasing trend of U.S. MMR may include poor data quality due to the lack of interoperability of $\mathrm{MM}$ measures and harmonization of reporting artifacts over time (e.g., the evolution of cause-ofdeath codes for maternal death from ICD-1 to ICD-10 and use of the pregnancy checkbox on the death certificate); disparities in health care access and quality; increasing maternal age, coupled with high prevalence of comorbid conditions surrounding pregnancies and pregnancy-associated conditions (e.g., gestational diabetes, preeclampsia); and other social determinants of health $(\mathrm{SDOH}) .^{3,29-34}$

Several analyses of national, state, and local data demonstrate disparities in MM by sociodemographic factors (e.g., race, ethnicity, age, education level, marital status, health insurance), geographic areas (e.g., rural vs. urban), and states. $^{4,23,32,34-40}$ Regardless of the direction of the overall U.S. MMR trajectory over time, however, racial disparities in MM have persisted for more than 80 years (Fig. 1). Analyses of PMSS data from 2007 to 2016 showed that non-Hispanic Black (Black) women 40 years and older and American Indian/Alaska Native (AI/AN) women 35-39 years of age had the highest PRMR at 189.7 and 104.2, respectively. Conversely, Hispanic women and Asian and Pacific Islander women age 20-24 had the lowest PRMRs at 7.0 and 7.2, respectively. Notably, the PRMR for Black women increased, and the Black-to-White Disparity Ratio (B:WDR) widened with increasing age, but PRMR did not decrease with higher education levels. ${ }^{23}$ Black women at all levels of income and education have a higher maternal death risk than non-Hispanic White (White) women. These disparities may be related to the "weathering" hypothesis, which proposes that Black women experience earlier deterioration of health because of the cumulative impact of exposure to the racial construct's psychosocial, economic, and environmental stressors. ${ }^{35}$ Additionally, PMSS data from 1998 to 2005 indicate that MMR for unmarried women was 1.7 times that of married women, and MMR for women with no prenatal care was 5 times that of women with any prenatal care. ${ }^{21}$ Studies have inversely associated increasing MM with family planning. ${ }^{32}$

Closure of gynecological and obstetrical care services and shortage of obstetricians and gynecologists in rural and underserved communities have become more acute lately. ${ }^{13,41,42}$ Women living in rural areas and low-income women continue to be at increased risk for pregnancy-related deaths. ${ }^{42}$ In 2015, an analysis of national data found that the MMR in rural areas was 29.4, 1.6 times higher than the MMR of 18.2 in large, central metropolitan areas. ${ }^{38}$ From 2014 to 
Box 2. Global and Domestic Strategies to Reduce Maternal Mortality in the United States

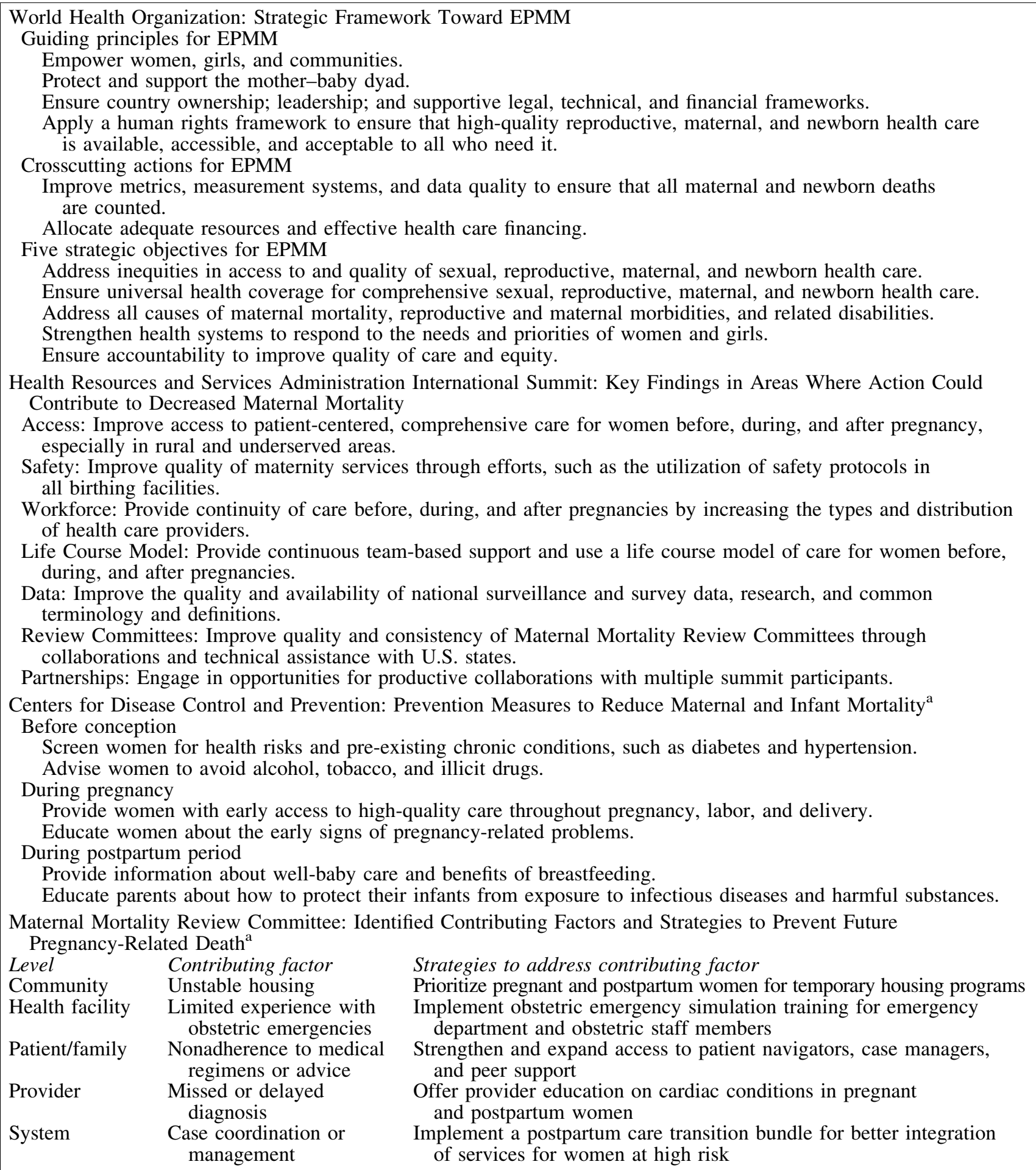

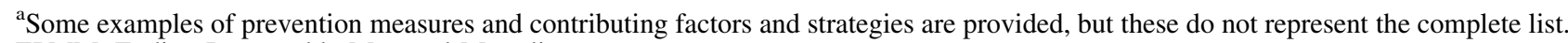
EPMM, Ending Preventable Maternal Mortality.

Source: Petersen et al..${ }_{27}^{4}$ World Health Organization, ${ }^{10}$ Health Resources and Services Administration (HRSA), ${ }^{12}$ and Centers for Disease Control and Prevention. ${ }^{27}$

2016, Washington state data showed that the MMR for rural residents was 1.5 times that of urban residents, and MMRs for women for whom no health insurance records could be located and women with Medicaid were, respectively, 12 and 3.5 times higher than those of women with private insur- ance. ${ }^{43}$ Analyses of NVSS and PMSS data have revealed both a wide range of MMRs among states and the District of Columbia and a consistently high B:WDR in every state and the district during 1987-2016, indicating that racial disparity remained a public health issue even in states with lower 


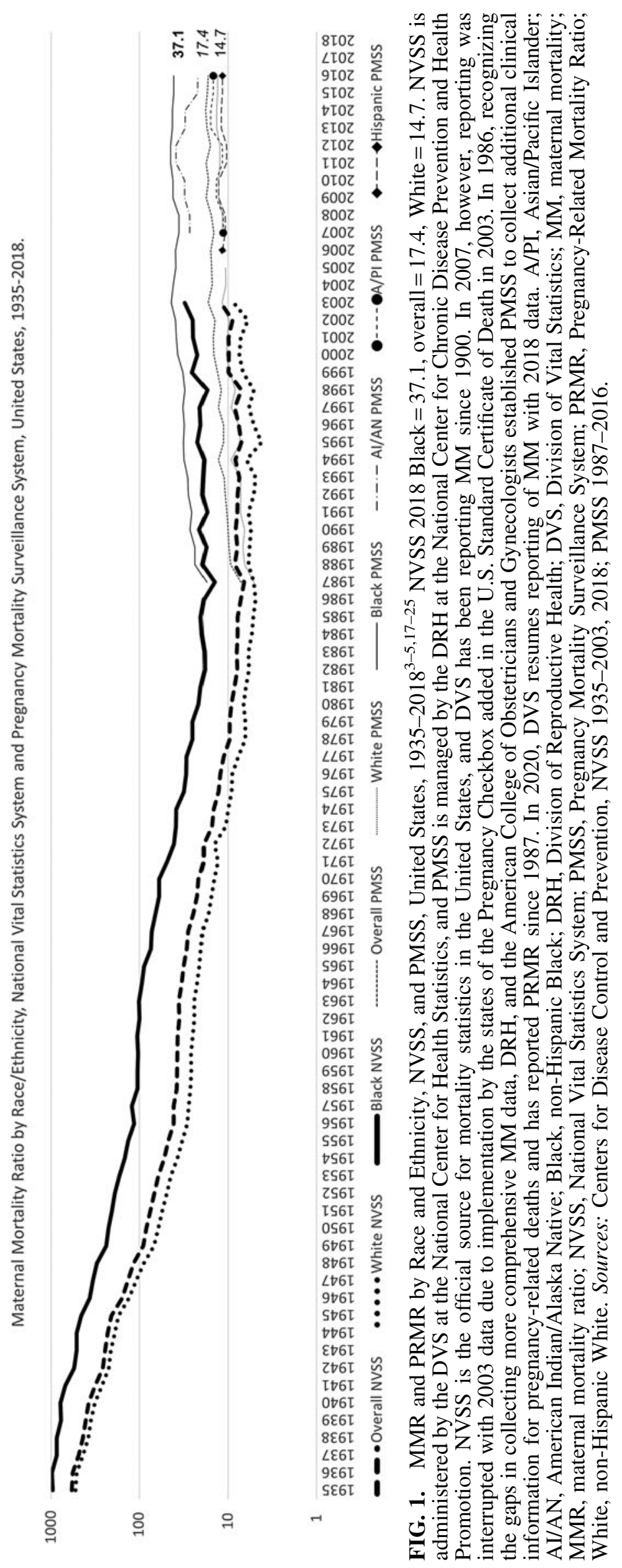


MMR. ${ }^{23,32,39}$ The differences in state MMRs involved many factors, including the structure and funding of maternal health services in each state and the composition of populations at high risk for MM. ${ }^{31}$

\section{Current State}

In 2020, DVS reported that 2018 data showed a total of 658 maternal deaths, MMR of 17.4, 277 late maternal deaths, and late MMR of 7.3. Nationwide MM disparities continued across subpopulations, states, and geographic areas. The MMR for Black women (37.1) was 2.5 times that of White women (14.7) and 3.1 times that of Hispanic women (11.8). The MMR for women age 40 and older (81.9) was 7.7 times that of women age 25 and younger (10.6). ${ }^{3}$ The District of Columbia and states with 10 or more reported maternal deaths had state-specific MMRs ranging from 9.7 to $45.9 .^{40}$ Based on analyses of recent PMSS data, maternal deaths occurred during pregnancy $(31 \%)$, at delivery (17\%), 1-42 days postpartum (40\%), and 43-365 days postpartum (12\%). About $60 \%$ of the maternal deaths were deemed preventable. The most common causes of maternal death included cardiovascular conditions (e.g., cardiomyopathy, hypertensive disorders of pregnancy, cerebrovascular accidents), infection, and hemorrhage. However, the cause-of-death proportions varied by timing of death and race/ethnicity of the women. ${ }^{4}$ Cardiomyopathy, thrombotic pulmonary embolism, and hypertensive disorders of pregnancy contributed more to pregnancy-related deaths among Black women than among White women. Hemorrhage and hypertensive disorders of pregnancy contributed more to pregnancy-related deaths among AI/AN women than among White women. ${ }^{23}$

Recently, stories about deaths of mothers and the dilemma the United States is facing with the steady rise and disparity of MM have gained attention in the news media. Many sectorsincluding the public; lawmakers and policymakers; federal, state, and local governments; academia; professional and women's health advocacy groups; and private and nonprofit entities-have undertaken new initiatives or enhanced ongoing efforts to reduce MM through collaboration and partnership (Table 2) ${ }^{24,25,44-57}$ Legislators in both the U.S. Senate and U.S. House of Representatives have introduced bills that focus on issues ranging from expanding awareness of MM disparity to extending current Medicaid coverage from 60 days to 1 year postpartum. ${ }^{44}$ The HHS Office on Women's Health is leading a trans-HHS workgroup to develop an action plan to improve health outcomes for America's mothers and babies and coordinate activities supported by the federal government.

The availability of services and type of health insurance a woman has, greatly influence her choice of health care provider. ${ }^{13}$ Medicaid is the nation's largest payor of perinatal care and is especially important in rural and underserved communities. Nevertheless, Medicaid provides coverage only up to 60 days postpartum. ${ }^{53}$ In 2018, the American College of Obstetricians and Gynecologists issued an Opinion endorsed by other maternal health care professional organizations to reinforce the importance of the "fourth trimester" and propose a new paradigm for postpartum care. ${ }^{58}$ One study showed that Medicaid expansion up to 1 year postpartum has been associated with 1.6 fewer maternal deaths per 100,000 women than states that did not expand Medicaid. ${ }^{59}$ In addition to expanding health care coverage for community-based maternity care by all payors, improving the quality of available health care is crucial for the reduction of MM. ${ }^{13}$ Several states and institutions have implemented both the State Perinatal Quality Collaboratives program and the HRSA-funded Alliance for Innovation on Maternal Health (AIM) program in their health care systems. ${ }^{50,60,61}$ The California Maternal Quality Care Collaborative, a public-private partnership, has implemented maternal quality improvement programs with a focus on hemorrhage and preeclampsia that have reduced the state MMR, but not the B:WDR, from 2006 to $2016 .^{36}$ Another system-based improvement in maternal safety that has been adopted by one-third of states is the incorporation of levels of maternal care criteria in the state perinatal guideline. This approach provided an effective strategy by specifying required resources and capabilities within an integrated system of riskappropriate care in a region. ${ }^{62}$

\section{Future Directions}

The following recommendations to reduce $\mathrm{MM}$ are based on trends and common themes identified through the review and assessment of the historical data and current literature.

\section{Establish a national taskforce on maternal morbidity and mortality}

Drivers of the upward trend of MM and its continuing disparities in the United States are not well understood and have challenged maternal health stakeholders. Although ongoing efforts to reduce MM led by public and private sectors are targeting multiple contributing factors, it is crucial that the United States establish a national task force on maternal morbidity and mortality to better coordinate and integrate the limited human and capital resources under a national call-toaction plan. This task force can set short-, medium-, and longterm goals using the strategies and innovative solutions that have proven effective in the United States and worldwide. ${ }^{4,10,12,27,35,60,63,64}$

\section{Minimize health disparities through innovations and cultural competency}

In communities of color, discriminatory policies and practices that affect the quality of their health care and standard of living should be examined and modified by designing appropriate and culturally tailored action plans to eliminate or minimize the influence of racism on such service systems as education, health care, housing, labor, and other SDOH. ${ }^{35}$ Innovative strategies that effectively reduce disparities in MM are needed. For example, the reduction of hypertensive disorder, a major cause of MM among minority women, can be accomplished by adapting novel, culturally tailored, and evidence-based approaches. In one instance, a clinical trial effectively lowered high blood pressure among Black men who were patrons of barbershops. Barbers, trained as health educators, screened and referred patrons with uncontrolled hypertension to medical professionals, including pharmacists trained in the management of hypertension. ${ }^{65}$

Disparity in accessing maternal health care in underserved communities can be alleviated by expanding the capacity of telehealth technologies and their utilization across the country. The Extension for Community Healthcare Outcomes (ECHO) project has used telehealth technology to 
Table 2. Examples of Maternal Health Stakeholder Efforts to Reduce Maternal Mortality

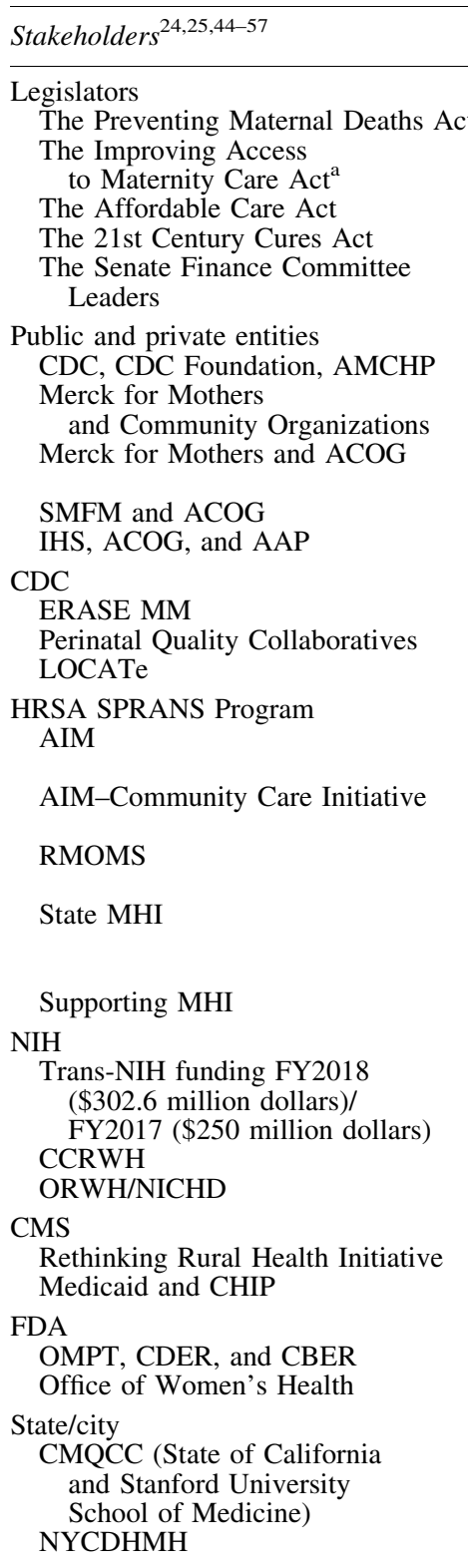

Description

Reauthorizes through FY2023 for CDC to provide support to tribal, state, and local MMRCs. Requires HRSA to identify maternity care health professional target areas.

Provides support for the HRSA's Maternal, Infant, and Early Childhood Visitation Program. Establishes Task Force on Research Specific to PRGLAC on safe and effective therapies.

Call to submit data and findings on factors contributing to poor maternal health outcomes in the United States.

Building U.S. capacity to review and prevent MM to remove barriers to fully functional MMRCs.

Safer Childbirth Cities Initiative to foster solutions led by local communities in helping cities to become safer and more equitable places to give birth.

Safe Motherhood Initiative to decrease MM by engaging health care providers and birthing facilities to develop and implement standard approaches for handling obstetric emergencies.

Joint consensus document that introduced a classification system for levels of maternal care.

Program to conduct-site visits and improve rural obstetrics care in the Indian health system.

Supports agencies and organizations that coordinate and manage MMRCs.

State or multistate networks of teams working to improve the quality of care for mothers and babies.

Helps states/jurisdictions create standardized assessments of levels of maternal and neonatal care.

Promotes the adoption and implementation of hospital-focused maternal safety bundles (evidencebased practices) for health care providers in birthing facilities and hospitals.

Supports the development, adoption, and implementation of nonhospital maternal safety bundles for health care providers in community-based organizations and outpatient settings.

Develops, tests, and implements service models, with the goal of improving access to, and continuity of, maternal and obstetrics care in rural communities.

Funds state-focused demonstration projects with three core functions: (1) establishing a state-focused Maternal Health Task Force, (2) improving state-level maternal health data and surveillance, and (3) promoting and implementing innovations in the health care delivery of maternal health care services.

Supports states, key stakeholders, and recipients of HRSA-administered awards.

Funded maternal health projects addressing scientific gaps such as risk prediction, severe morbidity, optimal timing for delivery, maternal long-term outcomes, and data collection.

Provides valuable guidance, collaboration, and support to ORWH program goals.

Launched MMM web portal and MMM booklet; sponsored MMM workshops and meetings.

Rural Health Strategy to have new health policies and initiatives positively impact rural communities. Scorecard to evaluate state progress on maternal health outcomes.

Issued Postapproval Pregnancy Safety Studies Guidance for Industry in 2019.

Provides resources for consumers about food safety and medication use during pregnancy.

Expanded Maternal Quality Improvement Toolkits in areas of substance exposure, sepsis, venous thromboembolism, and cardiovascular disease.

Five-year plan to improve MM disparity through city-wide hospital quality improvement network, comprehensive maternity care in NYC health system, enhancement of data quality, and timeliness and public awareness campaign.

AAP, American Academy of Pediatrics; ACOG, American College of Obstetricians and Gynecologists; AIM, Alliance for Innovation on Maternal Health; AMCHP, Association of Maternal and Child Health Programs; CBER, Center for Biologics Evaluation and Research; CCRWH, Coordinating Committee on Research on Women's Health; CDC, Centers for Disease Control and Prevention; CDER, Center for Drug Evaluation and Research; CHIP, Children's Health Insurance Program; CMQCC, California Maternal Quality Care Collaborative; CMS, Centers for Medicaid and Medicare; ERASE MM, Enhancing Reviews and Surveillance to Eliminate Maternal Mortality; FDA, Food and Drug Administration; FY, fiscal year; HRSA, Health Resources and Services Administration; IHS, Indian Health Service; LOCATe, Levels of Care Assessment Tool; MHI, Maternal Health Innovation; MM, maternal mortality; MMM, Maternal Morbidity and Mortality; MMRCs, Maternal Mortality Review Committees; NICHD, National Institute of Child Health and Human Development; NIH, National Institutes of Health; NYCDHMH, New York City Department of Health and Mental Hygiene; OMPT, Office of Medical Products and Tobacco; ORWH, Office of Research on Women's Health; PRGLAC, Research Specific to Pregnant Women and Lactating Women; RMOMS, Rural Maternity and Obstetrics Management Strategies; SMFM, Society for Maternal/Fetal Medicine; SPRANS, Special Projects for Regional and National Significance.

${ }^{\mathrm{a}}$ Amended the Public Health Service Act.

successfully expand specialized treatment to communities with shortages of specialty care through best practices protocols and primary care physician and specialist team efforts. ${ }^{66}$ This model can be adapted to enable maternal health providers in rural and underserved communities to provide obstetric specialty care to women at high risk of MM. Engaging communities in prevention efforts and supporting community-based programs that build social support and resiliency would likely improve patient-provider interaction, health communication, and health outcomes. ${ }^{35,67}$ 


\section{Invest in a diverse maternal health workforce}

To address the growing shortage of obstetricians and gynecologists in the United States, investments are needed to expand the maternity care workforce pipeline, including nurse midwives, physician assistants, nurse practitioners, family physicians, doulas, and community health workers. ${ }^{13}$ Doing so may increase the diversity, distribution, and size of maternal care in the United States. Although midwives constitute an important, safe, and cost-effective segment of maternity care, especially in rural areas, barriers to the practice of midwifery exist across the country. It is important to address the wide variation in regulation, certification, and licensing of maternity care professionals across the United States. In addition to clinicians, increasing the number of community health workers, public health practitioners, and researchers in the maternal morbidity and mortality arena is essential for the expansion of functional MMRC, community-based maternity care, and execution of the national research agenda. ${ }^{24,51,64}$

\section{Expand health care coverage using a life course model}

It is essential that Medicaid coverage be extended up to 1 year postpartum nationwide; this has been advocated by professional organizations. ${ }^{58}$ Pregnant women living in highincome countries with universal insurance coverage are not deprived of health care before, during, or after pregnancy. This access to universal coverage contributes to the low MMR observed in these countries. ${ }^{13}$

\section{Improve health care quality through respectful maternal and child care}

Because the majority of maternal deaths occur during pregnancy and at delivery-when most women have health care coverage - it is critical to improve the quality of health care by empowering women and communities and applying a human rights framework to protect and support mothers and babies. ${ }^{10}$ Health care systems can implement standardized protocols to address obstetric emergencies and quality improvement initiatives, such as provider education to reduce missed or delayed diagnoses and a maternal early warning system. ${ }^{68}$ Another approach is to engage nonphysician clinicians for continuity and coordination of care. Patient navigation and other health system-barrier interventions have worked well to dismantle obstacles to health care access and utilization. $^{69-71}$ As part of maternal and infant care integration, the AIM program has developed sets of standardized, bundled guidance supported by perinatal quality collaboratives, which are state-based initiatives that aim to improve the quality of care for mothers and infants. ${ }^{72}$ These quality care initiatives can be enhanced to address all causes of MM.

\section{Integrate health service, biomedical, behavioral, and social sciences research}

Research is pivotal in advancing the understanding of the complex public health issues contributing to MM, and continued research is needed to address scientific gaps and identify effective and innovative evidence-based solutions. ${ }^{51,64} \mathrm{~A}$ coordinated research agenda can be developed by a multidisciplinary team of experts from public, private, community, and advocacy organizations using a common research platform.
More research is needed to elucidate biological disease processes; identify social and behavioral influences; design clinical interventions; and generate innovative solutions to address demographic and socioeconomic risk factors, racial and ethnic disparities, and other health system factors that increase maternal morbidity and mortality. Specific and innovative health services research applying rigorous data science will be key to making empirically grounded advances in maternal health outcomes in the United States. "Big Data" analytics that encourage interoperability and harmonization of women's health and maternal morbidity and mortality metrics, without disenfranchising minority and underserved populations, will be key to advancing our understanding of the issues contributing to the larger problem of MM.

\section{Conclusion}

The disparities in MM continue to be a public health challenge, even in those U.S. states, where the overall MMR has been reduced. A national task force is needed to coordinate and integrate diverse efforts led by maternal health stakeholders to decrease health disparities and reduce the U.S. MMR to a level similar to those reported in other high-income countries.

\section{Disclaimer}

The findings and perspectives in this article are those of the authors and do not necessarily represent the official position of the National Institutes of Health, the Health Resources and Services Administration, or the Harvard T.H. Chan School of Public Health.

\section{Author Disclosure Statement}

No competing financial interests exist.

\section{Funding Information}

No funding was received for this article.

\section{References}

1. World Health Organization (WHO). Reproductive health indicators: Guidelines for their generation, interpretation and analysis for global monitoring. Geneva: WHO Press, 2006:16-20.

2. World Health Organization (WHO). Trends in maternal mortality, 2000 to 2017: Estimates by WHO, UNICEF, UNFPA, World Bank Group and the United Nations Population Division. Geneva: WHO Press, 2019.

3. Hoyert DL, Miniño AM. Maternal mortality in the United States: Changes in coding, publication, and data release, 2018. National Vital Statistics Reports 2020;69. Hyattsville, MD: National Center for Health Statistics, 2020.

4. Petersen EE, Davis NL, Goodman D, et al. Vital signs: Pregnancy-related deaths, United States, 2011-2015, and strategies for prevention, 13 states, 2013-2017. MMWR Morb Mortal Wkly Rep 2019;68:423-429.

5. St. Pierre A, Zaharatos J, Goodman D, Callaghan WM. Challenges and opportunities in identifying, reviewing, and preventing maternal deaths. Obstet Gynecol 2018;131:138-142.

6. Davis NL, Smoots AN, Goodman DA. Pregnancy-related deaths: Data from 14 U.S. Maternal Mortality Review Committees, 2008-2017. Atlanta, GA: Centers for Disease Control and Prevention, 2019. Available at: https://www 
.cdc.gov/reproductivehealth/maternal-mortality/erase-mm/ MMR-Data-Brief_2019-h.pdf Accessed July 6, 2020.

7. World Health Organization (WHO). Trends in maternal mortality, 1990 to 2015: Estimates by WHO, UNICEF, UNFPA, World Bank Group and the United Nations Population Division. Geneva: WHO Press, 2015.

8. United Nations. The millennium development goals report. New York, 2015. Available at: https://www.un.org/en/ development/desa/publications/mdg-report-2015.html Accessed July 6, 2020.

9. United Nations. Transforming our world: The 2030 agenda for sustainable development. New York, 2015. Available at: https://sustainabledevelopment.un.org/post2015/transform ingourworld/publication Accessed July 6, 2020.

10. World Health Organization. Strategies towards ending preventable maternal mortality (EPMM). Geneva: WHO Press, 2015.

11. Knight M, Bunch K, Tuffnell D, et al., eds. on behalf of MBRRACE-UK. Saving lives, improving mothers' care: Lessons learned to inform maternity care from the UK and Ireland confidential enquiries into maternal deaths and morbidity, 2015-17. Oxford: University of Oxford, 2019.

12. Health Resources and Services Administration (HRSA). HRSA maternal mortality summit, June 19-21, 2018: Promising global practices to improve maternal health outcomes technical report. February 15, 2019. Available at: https://www.hrsa.gov/sites/default/files/hrsa/maternal-mortality/ Maternal-Mortality-Technical-Report.pdf Accessed July 6, 2020.

13. National Academies of Sciences Engineering and Medicine. Birth settings in America: Outcomes, quality, access, and choice. Washington, DC: The National Academies Press, 2020.

14. National Center for Health Statistics. Healthy People 2000 final review. Hyattsville, MD: Public Health Service, 2001.

15. National Center for Health Statistics. Healthy People 2010 final review. Hyattsville, MD: Public Health Service, 2012.

16. National Center for Health Statistics. Chapter 26 Maternal, Infant, and Child Health (MICH). In Healthy People 2020: Midcourse review. Hyattsville, MD: Public Health Service, 2017:1-37.

17. Hoyert DL. Maternal mortality and related concepts. Vital Health Stat 2007;3:1-13.

18. Chang J, Elam-Evans LD, Berg CJ, et al. Pregnancy-related mortality surveillance-United States, 1991-1999. MMWR Surveill Summ 2003;52:1-8.

19. Berg CJ, Atrash HK, Koonin LM, Tucker M. Pregnancyrelated mortality in the United States, 1987-1990. Obstet Gynecol 1996;88:161-167.

20. Berg CJ, Chang J, Callaghan WM, Whitehead SJ. Pregnancy-related mortality in the United States, 19911997. Obstet Gynecol 2003;101:289-296.

21. Berg CJ, Callaghan WM, Syverson C, Henderson Z. Pregnancy-related mortality in the United States, 1998 to 2005. Obstet Gynecol 2010;116:1302-1309.

22. Creanga AA, Berg CJ, Syverson C, Seed K, Bruce FC, Callaghan WM. Pregnancy-related mortality in the United States, 2006-2010. Obstet Gynecol 2015;125:5-12.

23. Petersen EE, Davis NL, Goodman D, et al. Racial/ethnic disparities in pregnancy-related deaths, United States, 20072016. MMWR Morb Mortal Wkly Rep 2019;68:762-765.

24. Zaharatos J, St Pierre A, Cornell A, Pasalic E, Goodman D. Building U.S. capacity to review and prevent maternal deaths. J Womens Health 2018;27:1-5.
25. Centers for Disease Control and Prevention. Maternal mortality. Available at: https://www.cdc.gov/reproductivehealth/ maternal-mortality/pregnancy-mortality-surveillance-system .htm Accessed July 6, 2020.

26. Kozhimannil KB, Interrante JD, Corbett A, Heppner S, Burges J, Henning-Smith C. Rural focus and representation in state Maternal Mortality Review Committees: Review of policy and legislation. Womens Health Issues 2019;29:357-363.

27. Centers for Disease Control and Prevention. Healthier mothers and babies. MMWR Morb Mortal Wkly Rep 1999; 48:849-858.

28. Callaghan WM. Overview of maternal mortality in the United States. Semin Perinatol 2012;36:2-6.

29. Neggers YH. Trends in maternal mortality in the United States. Reprod Toxicol 2016;64:72-76.

30. Rossen LM, Womack LS, Hoyert DL, Anderson RN, Uddin SFG. The impact of the pregnancy checkbox and misclassification on maternal mortality trends in the United States, 1999-2017. National Center for Health Statistics. Vital Health Stat 2020;3:1-49.

31. Moaddab A, Dildy GA, Brown HL, et al. Health care disparity and pregnancy-related mortality in the United States, 2005-2014. Obstet Gynecol 2018;131:707-712.

32. Hawkins SS, Ghiani M, Harper S, Baum CF, Kaufman JS. Impact of state-level changes on maternal mortality: A population-based, quasi-experimental study. Am J Prev Med 2020;58:165-174.

33. Sullivan SA, Hill EG, Newman RB, Menard MK. Maternal-fetal medicine specialist density is inversely associated with maternal mortality ratios. Am J Obstet Gynecol 2005; 193(Pt 2):1083-1088.

34. Nelson DB, Moniz MH, Davis MM. Population-level factors associated with maternal mortality in the United States, 1997-2012. BMC Public Health 2018;18:1007.

35. Howell EA. Reducing disparities in severe maternal morbidity and mortality. Clin Obstet Gynecol 2018;61:387-399.

36. Main EK, Markow C, Gould J. Addressing maternal mortality and morbidity in California through public-private partnerships. Health Aff 2018;37:1484-1493.

37. New York City Department of Health and Mental Hygiene. Bureau of Maternal, Infant and Reproductive Health. Pregnancy-associated mortality, New York City: 2006-2010. Available at: https://www1.nyc.gov/assets/doh/downloads/ pdf/ms/pregnancy-associated-mortality-report.pdf Accessed July 6, 2020.

38. Maron D. Maternal health care is disappearing in rural America. Scientific American, 2017. Available at: https:// www.scientificamerican.com/article/maternal-health-care-isdisappearing-in-rural-america Accessed July 6, 2020.

39. Centers for Disease Control and Prevention. State-specific maternal mortality among black and white women-United States, 1987-1996. MMWR Morb Mortal Wkly Rep 1999; 48:492-496.

40. Centers for Disease Control and Prevention, National Center for Health Statistics. Maternal mortality by state, 2018. Available at: https://www.cdc.gov/nchs/maternal-mortality/ MMR-2018-State-Data-508.pdf Accessed July 6, 2020.

41. Hung P, Henning-Smith CE, Casey MM, Kozhimannil KB. Access to obstetric services in rural counties still declining, with 9 percent losing services, 2004-2014. Health Aff 2017;36:1663-1671.

42. Kozhimannil KB, Interrante JD, Henning-Smith C, Admon LK. Rural-urban differences in severe maternal morbidity and mortality in the US, 2007-2015. Health Aff. 2019;38:2077-2085. 
43. Washington State Department of Health. Washington state maternal mortality review panel: Maternal deaths 20142016. 2019. Available at: https://www.doh.wa.gov/Portals/ 1/Documents/Pubs/141-010-MMRPMaternalDeathReport 2014-2016.pdf Accessed July 6, 2020.

44. Library of Congress. Current legislative activities. Available at: https://www.congress.gov Accessed July 6, 2020.

45. U.S. Senate Committee on Finance. Grassley, Wyden seek information, solutions to improve maternal health. 2020. Available at: https://www.finance.senate.gov/chairmansnews/grassley-wyden-seek-information-solutions-to-improvematernal-health Accessed July 6, 2020.

46. Merck. Merck for mothers: Safer childbirth cities initiative, call to action to reverse the rise in U.S. maternal deaths. October 1, 2018. Available at: https://www.merckformothers .com/SaferChildbirthCities Accessed July 6, 2020.

47. American College of Obstetricians \& Gynecologists. 201316 safe motherhood initiative report. Available at: https:// www.acog.org/community/districts-and-sections/district-ii/ programs-and-resources/safe-motherhood-initiative Accessed July 6, 2020.

48. American College of Obstetricians and Gynecologists and Society for Maternal-Fetal Medicine. Obstetric Care Consensus No. 9: Levels of maternal care. Obstet Gynecol 2019;134:883.

49. Indian Health Service (IHS). IHS fact sheet: Maternal mortality and morbidity in Indian country. Available at: https://www.ihs.gov/dccs/mch Accessed July 6, 2020.

50. Congressional Research Service. Health Resources and Services Administration (HRSA): Maternal health programs. March 20, 2020. R46256. Available at: https:// crsreports.congress.gov Accessed July 6, 2020.

51. Chakhtoura N, Chinn JJ, Grantz KL, et al. Importance of research in reducing maternal morbidity and mortality rates. Am J Obstet Gynecol 2019;221:179-182.

52. National Institutes of Health, Office of Research on Women's Health. Maternal morbidity and mortality. Available at: https://orwh.od.nih.gov/research/maternal-morbidityand-mortality Accessed July 6, 2020.

53. Centers for Medicare \& Medicaid Services. Improving access to maternal health care in rural communities. Available at: https://www.cms.gov/About-CMS/Agency-Information/ OMH/equity-initiatives/rural-health/09032019-MaternalHealth-Care-in-Rural-Communities.pdf Accessed July 6, 2020.

54. U.S. Food \& Drug Administration. Postapproval pregnancy safety studies guidance for industry. 2019. Available at: https:// www.fda.gov/regulatory-information/search-fda-guidancedocuments/postapproval-pregnancy-safety-studies-guidanceindustry Accessed July 6, 2020.

55. U.S. Food \& Drug Administration. Office of Women's Health. Available at: https://www.fda.gov/about-fda/officecommissioner/office-womens-health Accessed July 6, 2020.

56. California Maternal Quality Care Collaborative. QI initiatives. Available at: https://www.cmqcc.org/qi-initiatives Accessed July 6, 2020.

57. NYC Health + Hospitals. Press Release: De Blasio administration launches comprehensive plan to reduce maternal deaths and life-threatening complications from childbirth among women of color. 2018. Available at: https://www .nychealthandhospitals.org/pressrelease/comprehensive-plantakes-maternal-safety-to-the-next-level Accessed July 6, 2020.
58. American College of Obstetricians and Gynecologists. ACOG Committee Opinion No. 736 Summary: Optimizing postpartum care. Obstet Gynecol 2018;131:949-951.

59. Searing A, Ross DC. Medicaid expansion fills gaps in maternal health coverage leading to healthier mothers and babies. Washington, DC: Georgetown University Health Policy Institute Center for Children and Families, 2019.

60. Main EK, Menard MK. Maternal mortality: Time for national action. Obstet Gynecol 2013;122:735-736.

61. Henderson ZT, Ernst K, Simpson KR, et al. The national network of state perinatal quality collaboratives: A growing movement to improve maternal and infant health. J Womens Health 2018;27:221-226.

62. Vladutiu CJ, Minnaert JJ, Sosa S, Menard MK. Levels of maternal care in the United States: An assessment of publicly available state guidelines. J Womens Health 2020;29: 353-361.

63. Mann S, Hollier LM, McKay K, Brown H. What we can do about maternal mortality-And how to do it quickly. N Engl J Med 2018;379:1689-1691.

64. Jain JA, Temming LA, D'Alton ME, et al. SMFM Special Report: Putting the "M" back in MFM: Reducing racial and ethnic disparities in maternal morbidity and mortality: A call to action. Am J Obstet Gynecol 2018;218:B9-B17.

65. Victor RG, Lynch K, Li N, et al. A cluster-randomized trial of blood-pressure reduction in black barbershops. N Engl J Med 2018;378:1291-1301.

66. Arora S, Thornton K, Murata G, et al. Outcomes of treatment for hepatitis $\mathrm{C}$ virus infection by primary care providers. N Engl J Med 2011;364:2199-2207.

67. Hagiwara N, Elston Lafata J, Mezuk B, Vrana SR, Fetters MD. Detecting implicit racial bias in provider communication behaviors to reduce disparities in healthcare: Challenges, solutions, and future directions for provider communication training. Patient Educ Couns 2019;102:1738-1743.

68. Mhyre JM, D'Oria R, Hameed AB, et al. The maternal early warning criteria: A proposal from the national partnership for maternal safety. Obstet Gynecol 2014;124:782-786.

69. Krok-Schoen JL, Oliveri JM, Paskett ED. Cancer care delivery and women's health: The role of patient navigation. Front Oncol 2016;6:2.

70. Corbett CM, Somers TJ, Nunez CM, et al. Evolution of a longitudinal, multidisciplinary, and scalable patient navigation matrix model. Cancer Med 2020;9:3202-3210.

71. Fouad MN, Acemgil A, Bae S, et al. Patient navigation as a model to increase participation of African Americans in cancer clinical trials. J Oncol Pract 2016;12:556-563.

72. Council on Patient Safety in Women's Health Care. Alliance for Innovation on Maternal Health. Safety health care for every women. 2015. Available at: https://safehealth careforeverywoman.org Accessed July 6, 2020.

Address correspondence to: Soju Chang, MD, MPH

Division of Clinical Innovation

National Center for Advancing Translational Sciences National Institutes of Health 6701 Democracy Boulevard, Room 914 Bethesda, MD 20892-4874 USA

E-mail: soju.chang@nih.hhs.gov 